\title{
Isometry in mesosaurs: Implications for growth patterns in early amniotes
}

Pablo Núñez Demarco, Jorge Ferigolo, and Graciela Piñeiro

Acta Palaeontologica Polonica 67 (2), 2022: 509-542 doi:https://doi.org/10.4202/app.00931.2021

Mesosaurs were small amphibious tetrapods that lived in western Gondwana during the Early Permian or even earlier, when temperate Permo-Carboniferous conditions initiated after the glaciations that affected the southern region of Pangea. In this contribution, we applied traditional linear regression morphometrics to analyse proportions of both the skull and limb bones in more than 100 mesosaur specimens. The analyses revealed that all mesosaur bones scale remarkably close to a model of geometrical similarity (isometry), and that this pattern is particularly strong in long bones and also in the skull. These results indicate that juvenile and adult mesosaurs do not display appreciable change in bone proportions, meaning that there are few or no noticeable differences between them during growth. The well-defined isometry, and particularly, the high interrelation between metatarsals and phalanges permit us to suggest that the mesosaur hind limb is subject to notable modularity. This evidence strongly argues that the differences previously described to support three mesosaur species in Western Gondwana, might instead reflect natural intraspecific variability, taphonomic features or even possible sexual dimorphism, as recently suggested. Our study also reinforces the general plesiomorphic structure of the mesosaur skeleton, which along with some cranial specializations for ecological fitness and the evidence of strong isometric growth as we demonstrate herein, may suggest new hypotheses of relationships for mesosaurs which thus would position them as more basal amniotes than previously thought.

Key words: Mesosauridae, Mesosaurus tenuidens, morphometrics, allometry, Permian, Gondwana, Pangea.

Pablo Núñez Demarco [pnunez@fcien.edu.uy], Instituto de Ciencias Geológicas, Facultad de Ciencias, Universidad de la República, Montevideo, Uruguay; InGeBa, Facultad de Ciencias Exactas y Naturales, Universidad de Buenos Aires (UBA), Intendente Güiraldes 2160, Buenos Aires, Argentina. Jorge Ferigolo [jorgeferigolo@gmail.com], Seção de Paleontologia, Museu de Ciências Naturais, Secretaria do Meio Ambiente e Infraestrutura do Rio Grande do Sul (SEMA), Rua Salvador França, 1427-90 690-000, Porto Alegre, RS, Brazil. Graciela Piñeiro [fossil@fcien.edu.uy], Departamento de Paleontología, Facultad de Ciencias, Iguá 4225. CP. 11400. Montevideo, Uruguay. 
This is an open-access article distributed under the terms of the Creative Commons

Attribution License (for details please see creativecommons.org), which permits unrestricted use, distribution, and reproduction in any medium, provided the original author and source are credited.

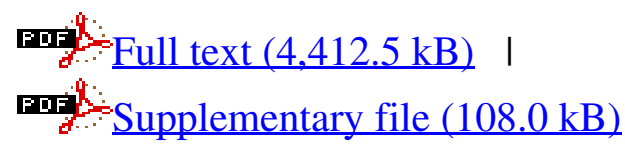

